\title{
Drive Train Design and Modeling of a Parallel Diesel Hybrid Electric Bus Based on AVL/Cruise
}

\author{
Yajuan Yang $^{1}$, Han Zhao ${ }^{1}$, and Hao Jiang ${ }^{1}$ \\ ${ }^{1}$ School of Mechanical and Automotive Engineering, Hefei University of Technology , Tunxi Road 193\# \\ Hefei, 230009, China, lily.yyj0903@gmail.com
}

\begin{abstract}
This paper aims at the parametric drive train design, modeling and performance simulation of a parallel diesel hybrid electric bus(PHEB). AVL/CRUISE and MATLAB/SIMULINK are used for modeling and simulation. The simulation tasks include fuel consumption calculation over the typical city bus drive cycle of China, maximum velocity calculation and acceleration time calculation. Based on the simulation results, a comparative analysis is performed on the portion of fuel consumption in the internal combustion engine consumption map. The simulation shows that the engine operates in a more efficient condition in the hybrid electric bus than that in the conventional bus. Thanks to the hybrid electric drive train system, both fuel economy and traction performance of the bus are enhanced in a considerable step. The simulation analysis fits test results on road and chassis dynamometer well.
\end{abstract}

Keywords: PHEB, Simulation, Control strategy, Fuel consumption, Dynamic performance

\section{Introduction}

In recent years, air pollution, as one of the most important environmental problems, has become increasingly serious with the flourishing of automobile industry. To protect the environment and enhance the air quality of big cities, many governments make numerous regulations to limit the emission and fuel consumption of vehicles, most of which make the traditional vehicle design and manufacture harder and harder. Electric vehicles(EVs) and hybrid electric vehicles(HEVs) are the most potential solutions of this problem. Meanwhile, people pay more and more attentions at EVs and HEVs because of the increasing shortage of global oil supplies and the skyrocketing oil price. All of these above appeal to research and design of EVs and HEVs in many institutes and companies.

HEVs are the most feasible solutions to meet the demands of both the environment and the consumers, for they have considerable reductions of fuel consumption and have equivalent performances of traction. There is a popular opinion among the automobile manufacturers that transit buses are especially suitable for hybrid drive train system. There are two major advantages of transit buses. The first one is that transit buses, unlike other vehicles, have predictable routes with frequent starts and stops that of great convenience for setting control strategies of drive train. Another advantage is that they have large available space for batteries and electric motors.

A great lot of hybrid electric buses(HEB) have been in service in many countries, such as UK, US, France and
China. Due to the impulse of government and call of market, Chinese automobile companies show great interests in research and manufacture of HEBs. Demonstration operations in the Beijing Olympic Games and several other big cities in China have gotten very positive feedback.

The purpose of this paper is to develop a set of hybrid electric propulsive system on the base of a conventional bus with an internal combustion engine(ICE). Main tasks include system configuration design, control strategy design, modeling and simulation, and comparing with the results of simulation and tests on road and chassis dynamometer.

\section{Configuration of the Hybrid Bus}

There are three typical categories of hybrid electric vehicles in configuration: Series, Parallel and Synthesis. They are different in the arrangement of components of the drive train. In the series pattern, the ICE charges energy storage elements via an electric generator while energy storage elements feed an electric motor that propels the vehicle. In the parallel pattern, an electric motor on the support of a group of energy storage element cells forms an independent propelling line that parallel the ICE drive train. These two drive lines join with a torque coupler and, technically speaking, can propel the vehicle independently. The synthesis pattern is an integration of the series and parallel. For the object in this program, a transit city bus, the parallel configuration is more suitable and practical. For one thing, in the parallel configuration, the ICE can propel the bus independently in case the electric pattern is 
unavailable. For another thing, it is simpler and more convenient for engineers to build a parallel hybrid electric system on the base of a conventional bus.

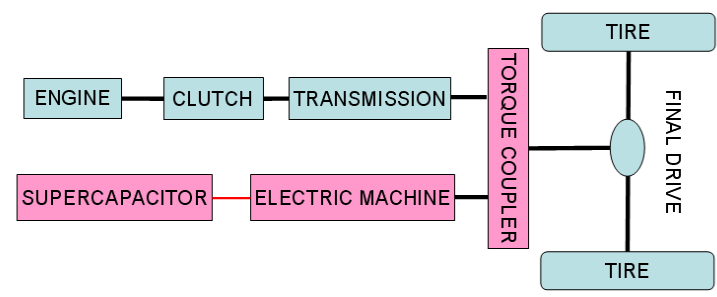

Figure 1: PHEB drive train configuration

As shown in figure 1, the green modules are conventional modules and the red modules are new modules which are set for electric propulsion system. This PHEB has two separated drivelines and each can drive the bus independently. The first driveline is just the same as the traditional drive pattern that has an engine, a clutch and a transmission system. Another driveline is composed of an energy storage element and an electric machine. Supercapacitor is chosen as the energy storage element for its expeditiously peaking power supply ability. In fact, the peak power capacity of the energy storage is more important than its energy capacity for a city bus because the frequent stop-and-go. These two drivelines are connected with a torque coupler. The basic parameters of the hybrid bus and conventional bus are given in table 1 .

Table 1: Basic parameters of the hybrid bus and conventional bus

\begin{tabular}{ccc}
\hline Parameters & Hybrid Bus & $\begin{array}{c}\text { Conventional } \\
\text { Bus }\end{array}$ \\
\hline Curb Weight & $11500 \mathrm{~kg}$ & $10980 \mathrm{~kg}$ \\
Gross Weight & $18000 \mathrm{~kg}$ & $17480 \mathrm{~kg}$ \\
Frontal Area & $8.1 \mathrm{~m} 2$ & $8.1 \mathrm{~m} 2$ \\
Drag Coefficient & 0.68 & 0.68 \\
Dynamic Rolling & $439 \mathrm{~mm}$ & $439 \mathrm{~mm}$ \\
Radius & & \\
Final Drive & 5.071 & 5.071 \\
Transmission & & \\
Ratio & & $7.8 \mathrm{~L}$ \\
Engine & $6.5 \mathrm{~L}$ & $199 \mathrm{~kW}$ \\
$\begin{array}{c}\text { Displacement } \\
\text { Engine Maximum } \\
\text { Power }\end{array}$ & $162 \mathrm{~kW}$ & \\
Engine Maximum & $2500[1 / \mathrm{min}]$ & $2500[1 / \mathrm{min}]$ \\
Speed &
\end{tabular}

\section{Conventional Bus Model}

Because the PHEB is built on the base of a conventional benchmarking bus, the configuration model of conventional bus is developed in AVL/Cruise in order to compare the fuel consumption and vehicle performance of PHEB with the conventional bus. AVL/Cruise is a comprehensive tool of vehicle simulation for calculating and optimizing of fuel consumption, emissions and vehicle performance. It is designed for modeling any kind of vehicle drive train configuration(including EVs, HEVs and fuel cell vehicles).

As shown in Figure2, the conventional bus model includes all components which are related to propulsion performance. The ICE is a six cylinder engine using diesel as fuel. The maximum speed is 2500 cycles per minute and peaking torque is $1080 \mathrm{Nm}$. Engine torque is turned into a friction clutch and then enters the manual five speed gear box. The final drive is built as a single ratio gear. The torque output of final drive enters the differential and changes directions to wheels. These components are connected with mechanical connections. The Conventional Bus component is the basic component of the model. The general data of the model such as the nominal dimensions and the weights are defined in this component. The cockpit component links the driver and the vehicle. It serves as a central controller to define the data and information of the driver and deliver drive commands to other components. The ASC(Anti Slip Control) component control the coefficient of friction of the wheels. The monitor component serves to show the chosen output values in the form of text while the calculation of the model is running.

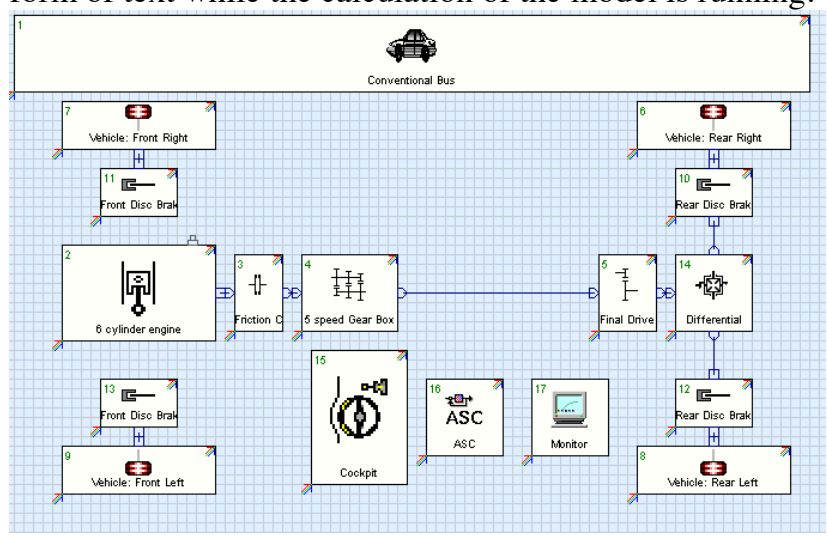

Figure 2: the conventional bus model in AVL/CRUISE

\section{Hybrid Bus Model}

The hybrid bus is manufactured by add a set of electric system on the base of the conventional bus. Since the electric propulsion system can help to enhance the dynamic performance of the vehicle, the displacement of the engine can be decreased in order to get a better fuel consumption data. The hybrid system includes a supercapacitor, a electric machine, a central controller and a torque coupler.

Figure 3 shows the hybrid bus model. The supercapacitor component is a chain of ten cells to support the required voltage of the electric machine. The electric machine component can be used either as an electric motor or as a generator. It charges the supercapacitor while braking or decelerating. The torque coupler is a pear of single ratio gears. The matlab dll component is an interface of MATLAB/SIMULINK to integrate cockpit and mechanical elements, such as engine and electric machine. 


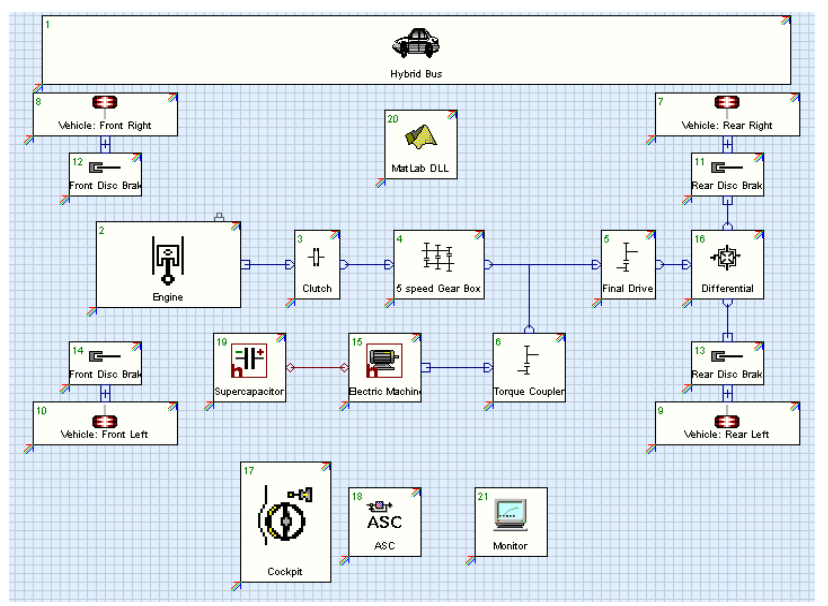

Figure 3: Model of PHEB in AVL/CRUISE

\section{Central Controller}

The control strategy is built in MATLAB/SIMULINK and embedded in the AVL/CRUISE model as an executable .DLL file via an interface component.

The PHEB drive train has five operating modes which are depending on the operation of the ICE and the electric machine. Which of these operating modes is used in real depends on the power demand, which is depended by the driver through the accelerate pedal or brake pedal, the SOC of the supercapacitor and vehicle velocity. The central controller receives the real-time signals from the driver, which in the simulation model is cockpit component, and other individual component, then commands the operation of each component according to the preset control logic.

A significant parameter of mode choosing is the torque of engine. The red line in Figure 4 is the expected engine operating points. Operating near this line will get a better fuel consumption result. Four basic operating modes are set for the purpose of fuel consumption reduction. And the fifth operating mode is switch off while both engine and electric machine are stopped.

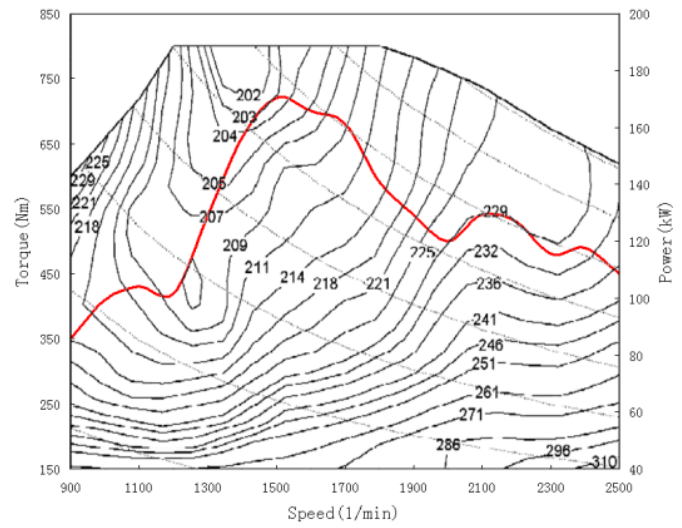

Figure 4: Engine characteristic map and expected engine operating points

The traditional drive mode is engine-alone traction mode. In this mode, the vehicle is propelled by the engine alone. This mode is used in three possible conditions. The first condition is that the desired torque of the vehicle is equal to the expected engine torque while the voltage of the supercapacitor is higher than the minimum discharge voltage. The second condition is that the desired torque of the vehicle is higher than the expected engine torque while the voltage of the supercapacitor is lower than the minimum discharge voltage. The third condition is that the desired torque of the vehicle is lower than the expected engine torque while the voltage of the supercapacitor is higher than the maximum charge voltage.

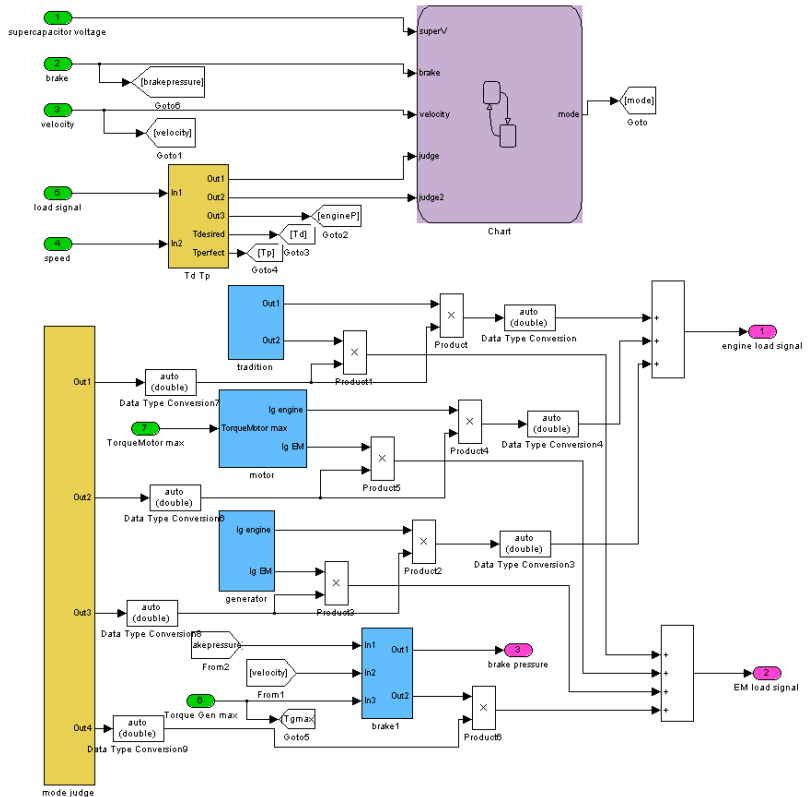

Figure 5: Central controller in MATLAB/SIMULINK

The hybrid drive mode is set for the situation that both the engine and the electric machine deliver traction power to the drive train. This mode is used when the desired torque of the vehicle is higher than the expected engine torque and the voltage of the supercapacitor is higher than the minimum discharge voltage.

The generator mode is supercapacitor charge mode. In this mode, the electric machine operates as a generator and is driven by the engine to charge the supercapacitor. This mode is used while the desired torque of the vehicle is lower than the expected engine torque and the voltage of the supercapacitor is lower than the maximum charge voltage.

The regenerative braking mode is set for the situation that the vehicle is braking. In this mode, the engine is shut down and the electric machine works as a generator and produces a braking torque to the drive train. Part of the kinetic energy of the vehicle mass is converted into electric energy and stored in the supercapacitor.

The control strategy built in MATLAB/SIMULINK is shown in figure 5. The controller uses a STATEFLOW chart to determine modes in which the vehicle is through real time input signals from AVL/CRUISE. The input signals include SOC(state of charge) of the supercapacitor, brake pressure from the cockpit, velocity of the vehicle, accelerator pedal signal of the driver and the speed of the engine. The controller demands components in AVL/CRUISE model through output signals. The output signals include load signal of engine, load signal of electric machine and brake pressures of four mechanical brakes.

\section{Results}


The typical cycle run of city bus in China is used to evaluate the fuel economy characteristics of the PHEB and compare it with the conventional bus. The total distance of this cycle run is 5890 meters. The maximum acceleration is $5 \mathrm{~m} / \mathrm{s} 2$. The average velocity is $16.13 \mathrm{~km} / \mathrm{h}$. Total time is 1314 seconds amount which in as long as 382 seconds the vehicle is stopped for 14 times and the engine is at idle speed. The cycle run is shown in figure 6 .

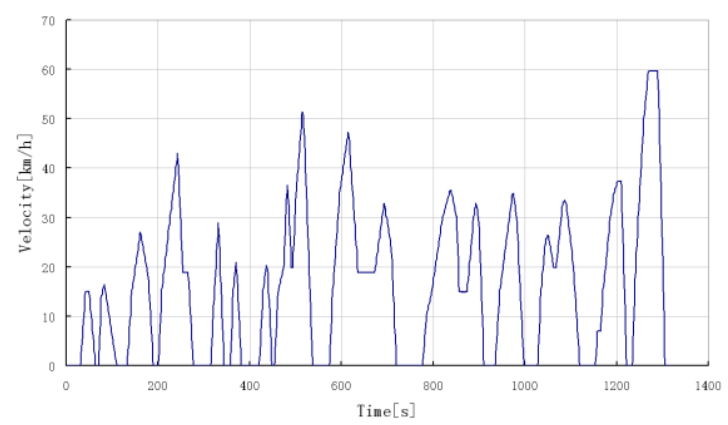

Figure 6: The typical cycle run of city bus in China

Figure 7 and 8 show the statistical percentage of engine operating region for hybrid and conventional bus respectively. Figure 9 and 10 show driving time distribution in consumption map for hybrid and conventional buses. Comparing these figures shows that the engine operates in a higher efficiency region for the hybrid bus and operates at low efficiency region for the conventional bus in most time.

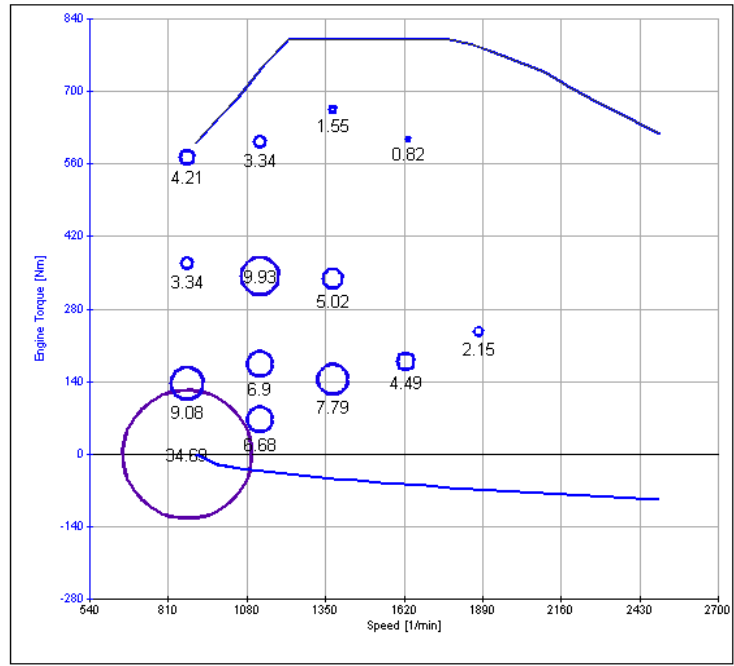

Figure 7: Statistical percentage of engine operating region for hybrid bus

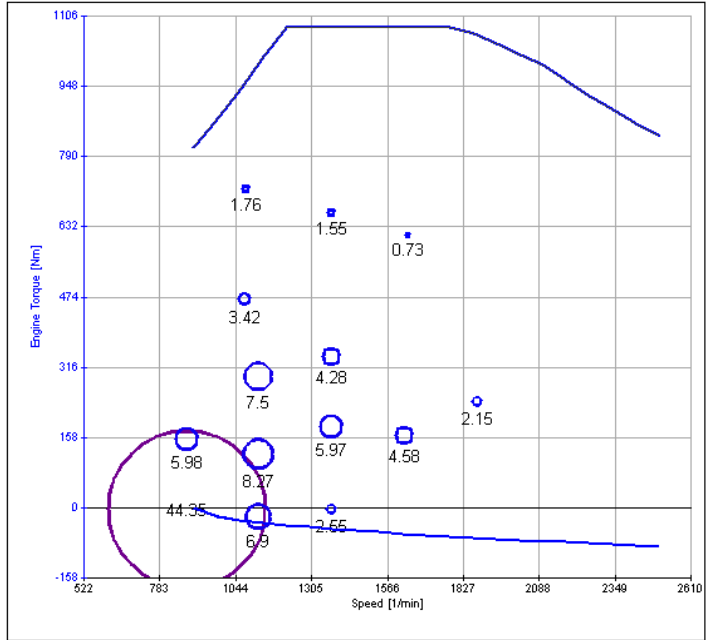

Figure 8: Statistical percentage of engine operating region for conventional bus

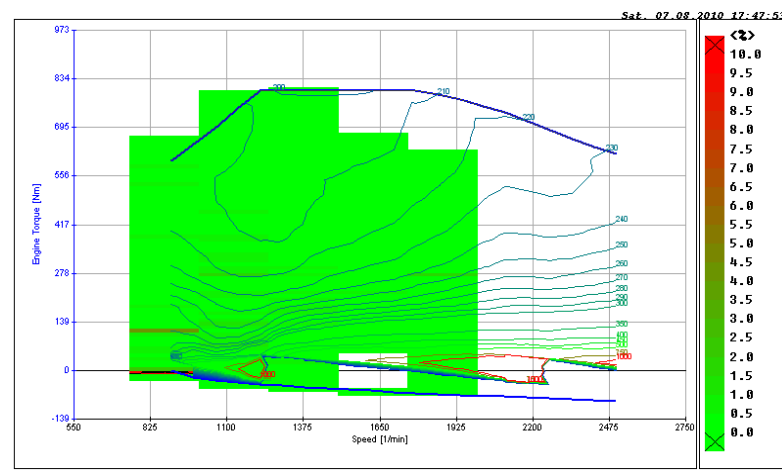

Figure 9: Driving time distribution in consumption map for hybrid bus

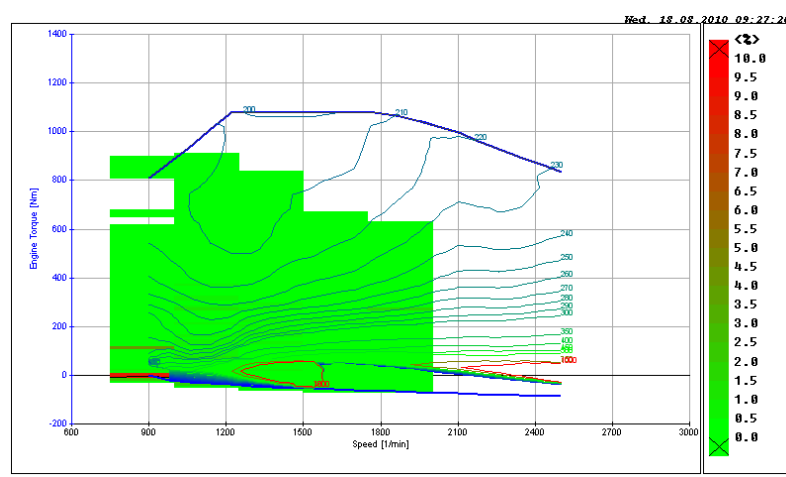

Figure 10: Driving time distribution in consumption map for conventional bus

Figure 11 and 12 present engine speed and torque of the hybrid bus in the drive cycle while figure 13 and 14 show the same outputs of the conventional bus. Because the engine speed is in direct proportion to the velocity determined by the drive cycle, the engine speeds of these two buses have same curves. For the hybrid bus, the engine torque is lower and it leads to less fuel consumption. 


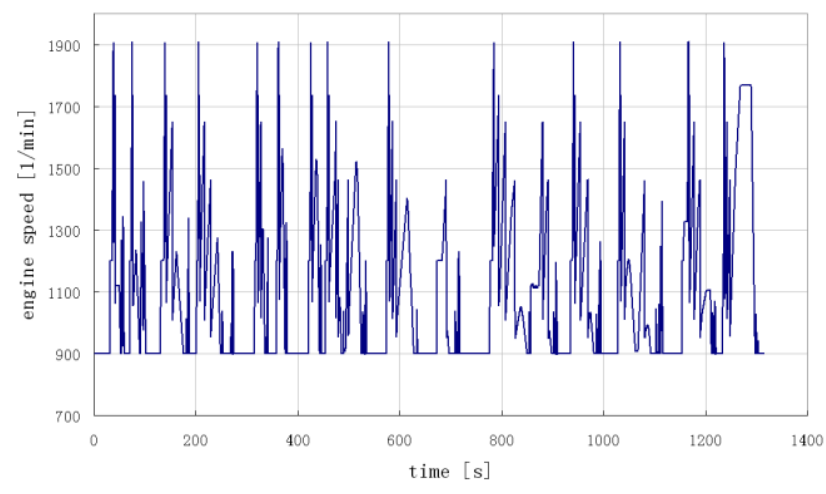

Figure 11: Engine speed for hybrid bus in drive cycle

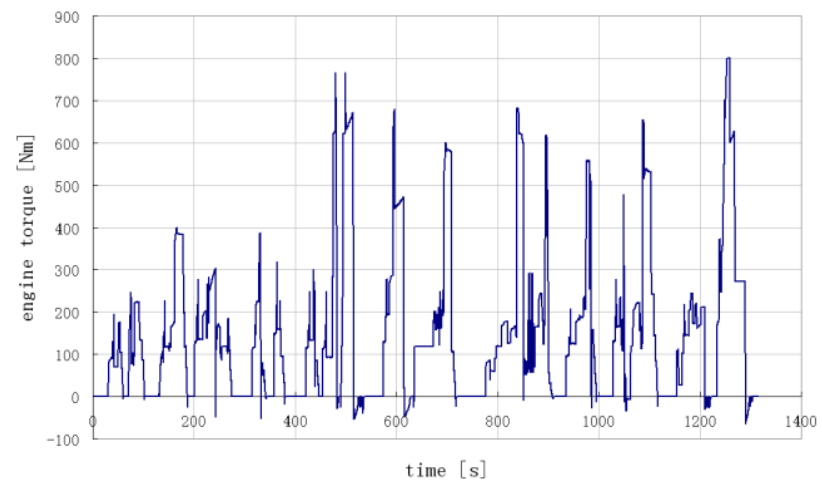

Figure 12: Engine torque for hybrid bus in drive cycle

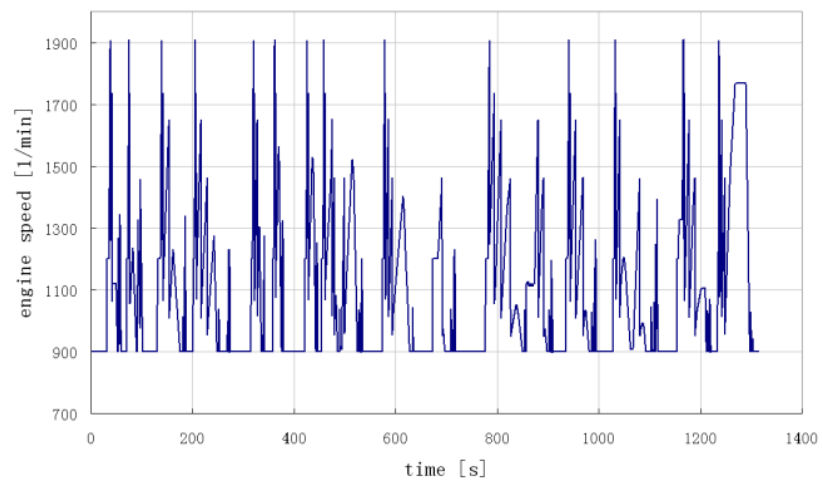

Figure 13: Engine speed for conventional bus in drive cycle

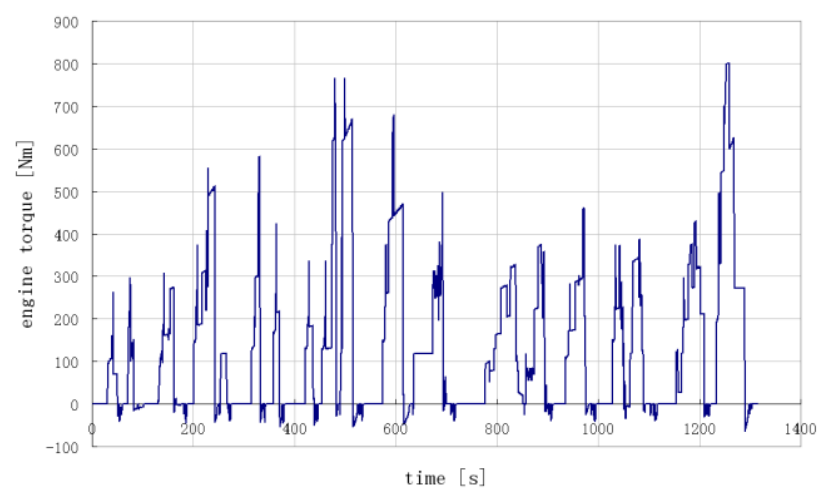

Figure 14: Engine torque for conventional bus in drive cycle

Figure 15 and 16 present the speed and torque of the electric machine. The speed curve is very similar to velocity curve of the drive cycle. In the accelerating periods, the torque of the electric machine is positive and helps to impel the vehicle. In the decelerating periods, the torque of the electric machine is negative and turn the mechanical energy to electric energy to charge the supercapacitor.

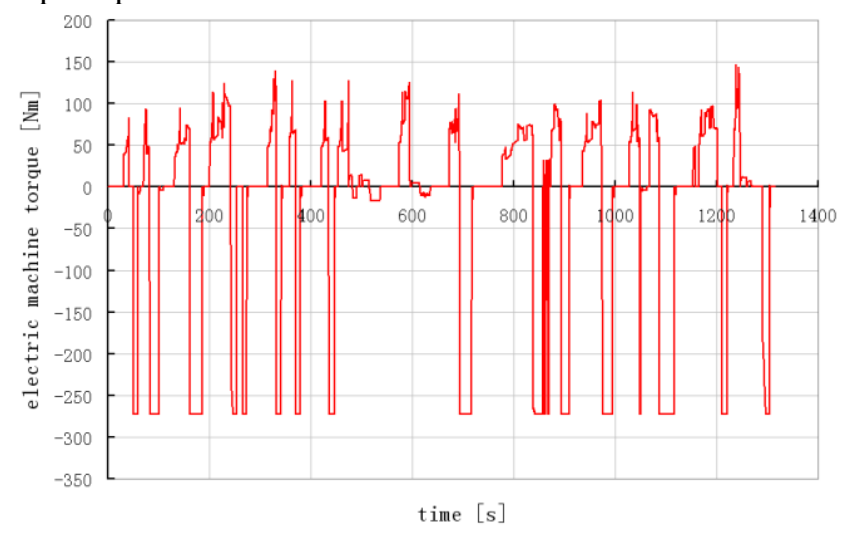

Figure 15: Electric machine torque for hybrid bus in drive cycle

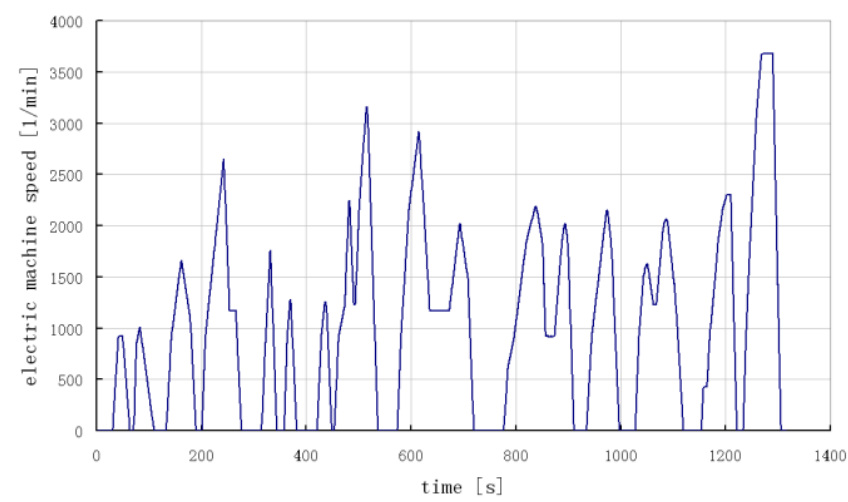

Figure 16: Electric speed torque for hybrid bus in drive cycle

Figure 17 shows the voltage and current of supercapacitor in the drive cycle. Figure 18 presents the SOC of the supercapacitor during the drive cycle. The SOC curves has a near balance value during the drive cycle. Since the control strategy for braking recovery is not faultless, the generator torque is more than the motor torque and the SOC curve has a slight rise.

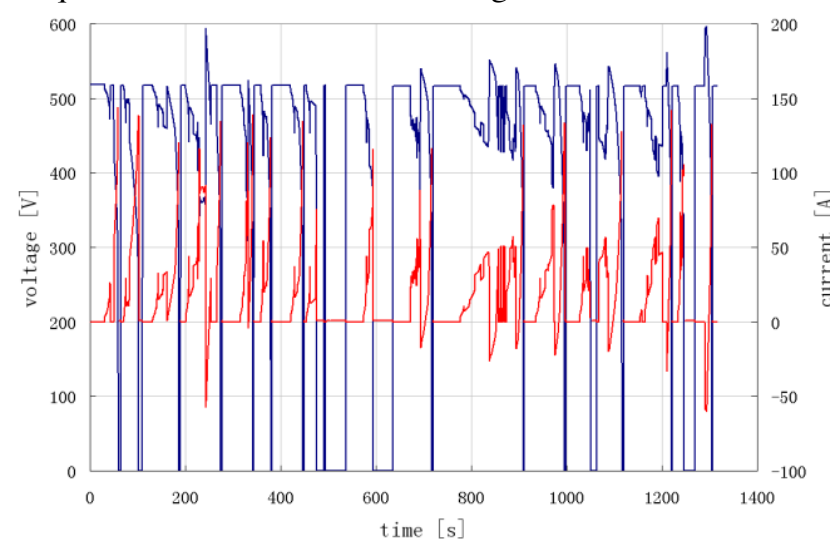

Figure 17: Voltage and current of supercapacitor in drive cycle

Figure 19 and 20 present velocity and acceleration curves from standstill to maximum velocity for the hybrid and conventional buses. Compared with the conventional bus, the hybrid bus has a higher acceleration and uses shorter time to get to its maximum velocity. 


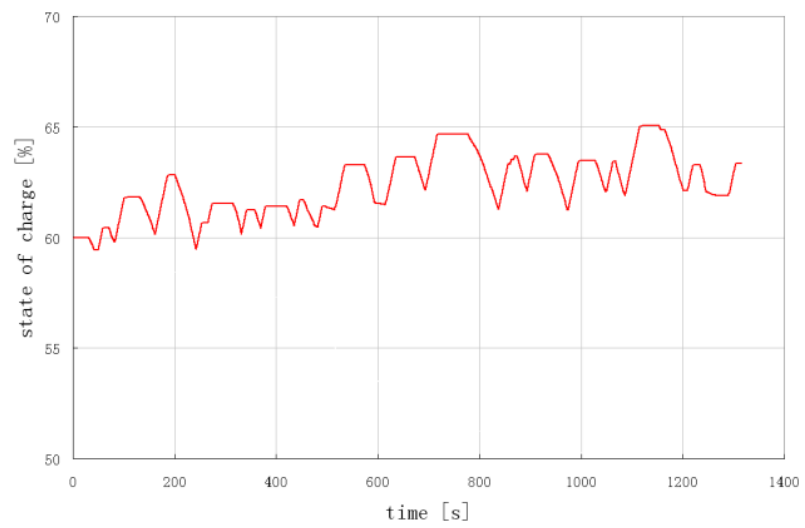

Figure 18: Supercapacitor state of charge during the drive cycle

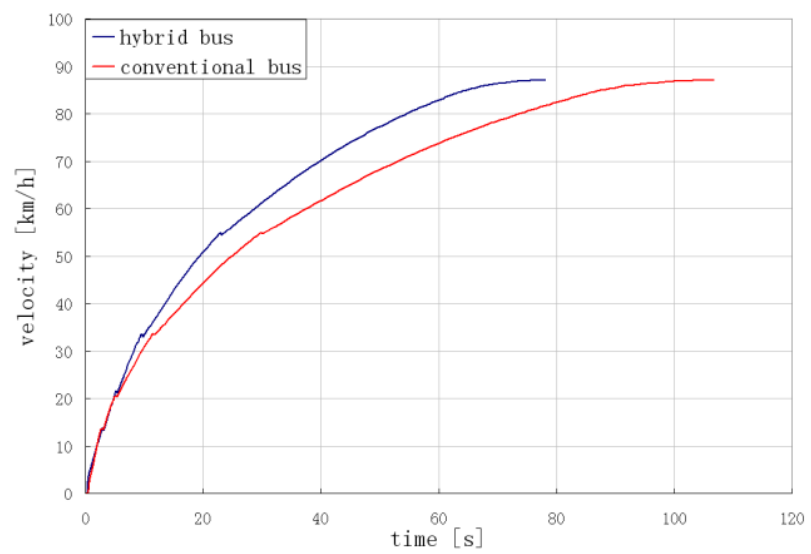

Figure 19: Velocity curves from standstill to maximum velocity for hybrid and conventional buses

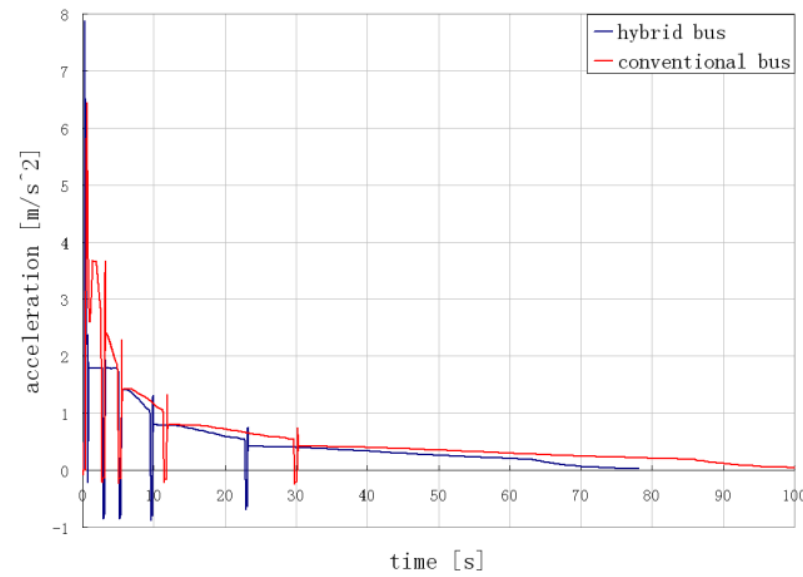

Figure 20: Acceleration curves from standstill to maximum velocity for hybrid and conventional buses

Table 2 shows results of simulations and tests. Compared with the conventional bus, the hybrid bus has a fewer fuel consumption and shorter acceleration time which present better fuel economy and dynamic performance.

\section{Conclusion and Future Work}

The main task of this paper is to design a electric hybrid drive system and compare it with the conventional one. Compared to the conventional bus, Simulation and test results show that the fuel consumption of the hybrid bus is decreased more than $10 \%$ by employing a downsized engine and operating the engine at high efficient regions The dynamic performance of the bus is improved apparently.

The hybrid vehicle shows to be a good alternative for conventional vehicles to decrease fuel consumption. However, it is not enough for the work. By optimizing the parameters of the drive line and employing suitable control strategies, the fuel economy and dynamic performance will be better.

Table 2. Simulation and test results comparison

\begin{tabular}{|c|c|c|c|c|}
\hline & \multicolumn{2}{|c|}{$\begin{array}{c}\text { Simulation } \\
\text { Results }\end{array}$} & \multicolumn{2}{c|}{ Test Results } \\
\hline & $\begin{array}{c}\text { Conven } \\
\text { tional }\end{array}$ & Hybrid & $\begin{array}{c}\text { Conven } \\
\text { tional }\end{array}$ & Hybrid \\
\hline $\begin{array}{c}\text { Fuel Consumption } \\
{[\mathrm{L} / 100 \mathrm{~km}]}\end{array}$ & 32.80 & 28.14 & 34.28 & 28.50 \\
\hline $\begin{array}{c}\text { Acceleration time } \\
\text { from standstill to } \\
50 \mathrm{~km} / \mathrm{h}[\mathrm{s}]\end{array}$ & 24.95 & 19.29 & 26.3 & 21.3 \\
\hline $\begin{array}{c}\text { Maximum } \\
\text { Velocity[km/h] }\end{array}$ & 84.3 & 84.3 & 81.2 & 83.2 \\
\hline
\end{tabular}

\section{Acknowledgments}

The authors would like to thank engineer Zhao Xiaofeng of Shanghai E-propulsion Auto Technology Co.Ltd for his support and tutoring.

\section{References}

[1]Liang Chu, Qingnian Wang, Minghui Liu and Jun Li, Parametric Design of Parallel Hybrid Power-train for Transit Bus, 2004 SAE World Congress, March 8-11,2004, pp:2

[2]Sheldon S. Williamson, Ali Emadi, Anshu Dewan, Effects of Varying Driving Schedules on the Drive Train Efficiency and Performance Characteristics of a Parallel Diesel-Hybrid Bus, Future Transportation Technology Conference, September 7-9, 2005,pp:1

[3]Yuh-Yih Wu, Bo-Chiuan Chen and K. David Huang, The Effects of Control Strategy and Driving Pattern on the Fuel Economy and Exhaust Emissions of a Hybrid Electric Bus, 2008 World Congress, April 14-17, 2008, pp:1

[4]Farhad Sangtarash, Vahid Esfahanian, Hassan Nehzati, Samaneh Haddadi, Meisam Amiri Bavanpour and Babak Haghpanah, Effect of Different Regenerative Braking Strategies on Braking Performance and Fuel Economy in a Hybrid Electric Bus Employing CRUISE Vehicle Simulation, 2008 World Congress, April 14-17, 2008, pp:830-831

[5]Samaneh Haddadi, Vahid Esfahanian, Hassan Nehzati, Farhad Sangtarash and Arash Akhgari, Effects of Drive-Train Hybridization on Fuel Economy and Dynamic Performance of a Series Hybrid Electric Transit Bus, 2008 SAE International Powertrains, Fuels and Lubricants Congress, June 23-25, 2008, pp:4-6

[6]Zeng Xiaohua, Wang Qingnian, Song Dafeng and Wang Weihua, System Design and Parameter Matching for the New Generation of Hybrid Electric City Bus, 2008 SAE World Congress,pp:843-845

[7]Mehrdad Ehsani, Yimin Gao, Ali Emadi, Modern Electric, Hybrid Electric, and Fuel Cell Vehicles Fundamentals, Theory, and Design, Power Electronics and Applications Series, CRC Press, 2010, pp:283-295 


\section{Author}

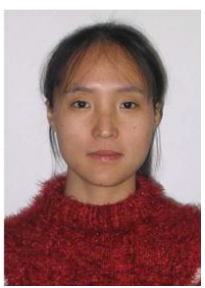

Ph.D candidate. Yajuan Yang

School of Mechanical and Automotive

Engineering, Hefei University of Technology,

Tunxi Road 193\#, Hefei, 230009, China

Tel: 086-13721046513

Email: lily.yyi0903@gmail.com

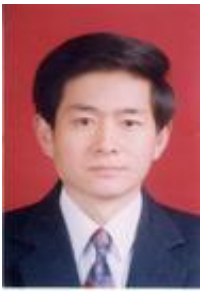

Vice President. Han Zhao

Hefei University of Technology, Tunxi Road

193\#, Hefei, 230009, China

Tel: 086-551-2901918

Email: hanzhao@mail.hf.ah.cn

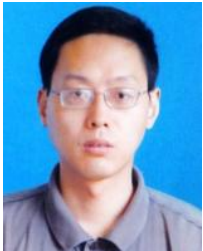

\section{Instructor. Hao Jiang}

School of Mechanical and Automotive

Engineering, Hefei University of Technology ,

Tunxi Road 193\#, Hefei, 230009, China

Tel: 086-13866700332

Email: jh_93@163.com 